\title{
Location of the Mandibular Foramen in Dry Mandibles: A Study in Southern Odisha
}

\author{
Rama Kristna Sahu ${ }^{1}$, Suchitra Panigrahi ${ }^{2}$ Bandana Rath ${ }^{3}$, Sadananda Rath ${ }^{4}$ \\ ${ }^{\prime}$ (Associate Professor Dept. of Anatomy, M.K.C.G. Medical College, Berhampur,Odisha) \\ ${ }^{2}$ Assistant Professor, Dept. Of Ophthalmology, MKCG Medical College and Hospital, Berhampur,Odisha) \\ ${ }^{3}$ (Associate Professor, Dept. of Pharmacology, M.K.C.G. Medical College, Berhampur,Odisha) \\ ${ }_{4}^{4}$ (Professor and HOD, Dept. of Anatomy, M.K.C.G. Medical College, Berhampur,Odisha)
}

*Corresponding author: Bandana Rath ${ }^{3}$ *

\begin{abstract}
:
Aim and objectives: Mandibular foramen is leading to mandibular canal through which inferior alveolar nerve and vessels transmit and supply the teeth of lower jaw. Inferior alveolar nerve block is a common local anaesthetic technique, prior to dental surgeries of lower jaw. Hence a precise anatomical knowledge is highly essential to locate the mandibular foramen for this nerve block.

Materials and method: 65 adult edentulous dry human mandibles of Southern Odisha of unknown age and sex were taken for descriptive study. Distance of mandibular foramen from mandibular notch, anterior border, posterior border and angle of mandible were measured by slide calliper, data were tabulated and analysed statistically.

Results: The mean distance of mandublar foramen to anterior border was $17.21 \mathrm{~mm}$ in right side and $17.0 \mathrm{~mm}$ in left side, to posterior border $16.1 \mathrm{~mm}$ in right side and $16.0 \mathrm{~mm}$ in left side, to the floor of the mandibular notch $20.8 \mathrm{~mm}$ in right side and $21.3 \mathrm{~mm}$ in left side. and to gonium $21.31 \mathrm{~mm}$ in right side and $20.34 \mathrm{~mm}$ in left side were obtained.

Conclusion: Localisation of mandibular foramen is an important pre-requisite prior to inferior alveolar nerve block during any mandibular surgery.
\end{abstract}

Keyword: Anterior border, mandibular angle, mandibular foramen, ramus of mandible, slide calliper

\section{Introduction}

The mandible is a Latin word which means lower jaw. Mandere means to chew. Thus the word mandible is derived. [1] It is an important bone of the face that forms the lower jaw. It has a ' $u$ ' shaped anterior part the body, ramus, condylar and coronoid process. Ramus of the mandible has two surfaces (Medial and lateral) and four borders (anterior, posterior, inferior and superior). [2] There is a mandibular notch in the superior border. The mandibular foramen is an irregular opening on the medial surface of the Ramus of the mandible nearly at the centre. [3] It leads into mandibular canal which traverses in the body of the mandible and opens to the outer surface as mental foramen and continues further in the body as incisive canal. The inferior alveolar nerve and vessels enter into mandibular canal and comes out through mental foramen and supply the roots of the tooth of the lower jaw. This mandibular foramen is guarded by a bony projection called lingula to which spheno-mandibular ligament is attached. The knowledge of the position of the mandibular foramen is very important for the dental surgeon in inferior alveolar nerve block for effective pain control in various surgical and dental operations on the mandible and tooth of lower jaw such as removal of impaction, reduction of fractures and extraction of tooth etc. The traditional Halsted approach is standard and common method of lower teeth anaesthesia by blocking of inferior alveolar nerve. In this approach anaesthetic solution is injected in infratemporal space near inferior alveolar nerve. [4] Inferior alveolar nerve block failure is not uncommon and it occurs even with experienced hand. [5-7] Failure with this procedure could be as high as $45 \%$. For this idea of position, play an important role for successful inferior alveolar nerve block which is based on the precise anatomical knowledge of the correct location of the mandibular foramen.

Studies have been shown racial difference in the anatomy of mandible among the three major racial phenotypes of Caucasoid, Mongoloid and Negroid with a significant difference in metric, morphological and biological factors. The mandibular foramen is often selected as a reference point to stabilise the relation with the base of the mandible to establish racial differentiation. $[8,9]$

With this view, the present work was aimed to localise the mandibular foramen in an apparently accurate position which will help in approximating the needle tip position of the local anaesthetic injection for successful inferior alveolar nerve block, which will help the lower jaw dental procedure smooth and easy for both the surgeon and the patient. 


\section{Materials And Method}

For the study, 65 dry human mandibles of unknown sex were collected from the department of Anatomy, M.K.C.G. Medical College, Odisha. The bones were selected free from any pathological features or fractures. Completely dentulous mandible without absorbed alveolar margins were taken into consideration. The following parameters were taken to establish the correct position of mandibular foramen. All the distances were measured from centre of mandibular foramen (MF) to different bony landmarks on both sides of mandible by slide callipers. [3]These are

1) MN-MF-Distance from the lowest point of mandibular notch (MN) to the midpoint of mandibular foramen (MF).

2) AB-MF-Distance from the anterior border $(\mathrm{AB})$ of the ramus of the mandible to the midpoint of mandibular foramen.

3) PB-MF-Distance from the midpoint of the mandibular foramen (MF) to the nearest point on the posterior boarder $(\mathrm{PB})$ of the mandibular ramus.

4) MA-MF-Distance from the midpoint of mandibular foramen to the angle of the mandible (MA), Gonium.

Statistical analysis: The measurements were noted and descriptive statistics were performed using Graph pad Prism version 7.0

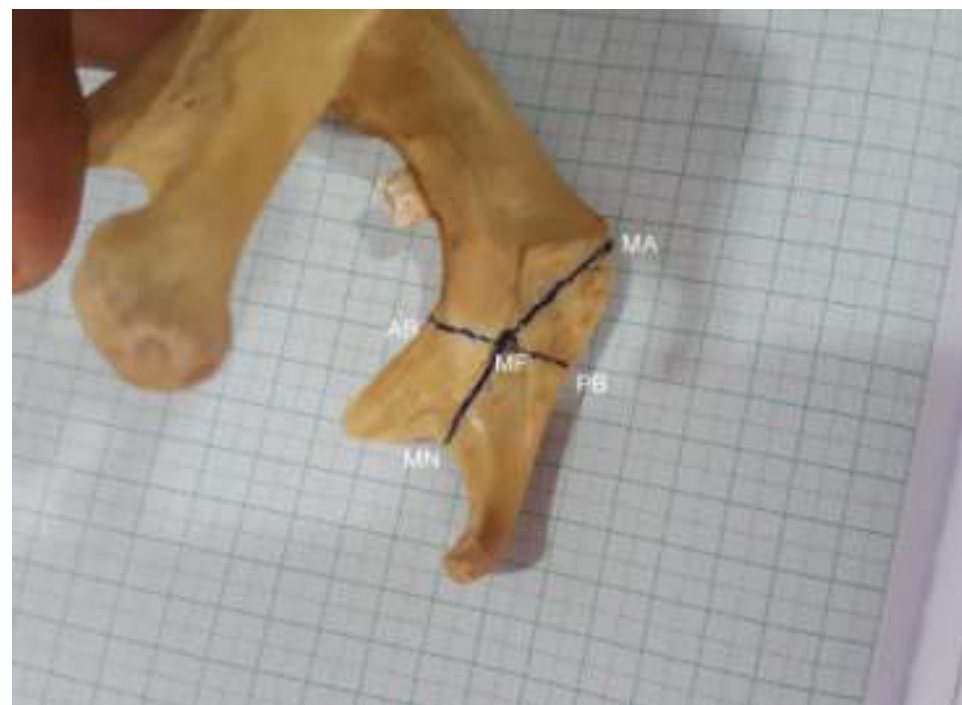

Fig 1-: Distance of mandibular foramen from various landmarks

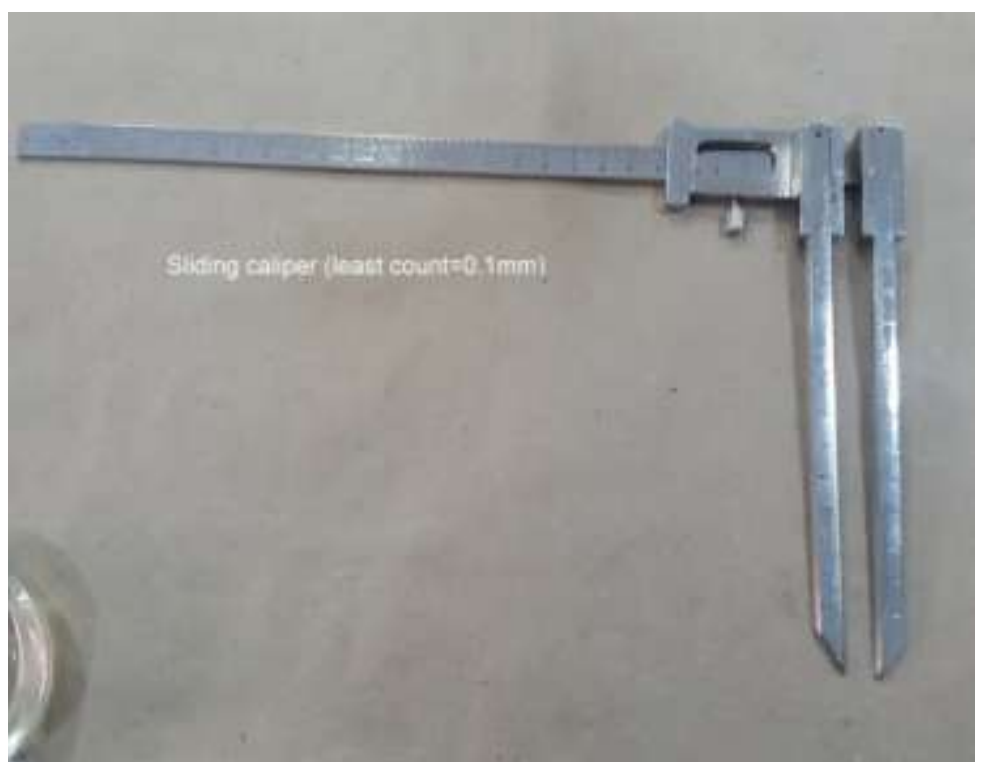

Fig-2: Slide callipers used for measuring distance of mandibular foramen from various landmarks 


\section{Observation and Results}

Table-I: Distance of the mandibular foramen from various landmarks

\begin{tabular}{|c|c|c|c|c|}
\hline \multirow{2}{*}{ Distance } & Side & Min - Max (mm) & Mean( mm) & $\begin{array}{c}\text { Standard } \\
\text { Deviation } \\
\text { (SD) }\end{array}$ \\
\hline \multirow{2}{*}{$\mathrm{AB}-\mathrm{MF}$} & Right & $13.3-21.5$ & 17.21 & 1.81 \\
\cline { 2 - 5 } & Left & $11.0-26.2$ & 17.0 & 2.61 \\
\hline \multirow{2}{*}{ PB - MF } & Right & $12.3-20.5$ & 16.1 & 1.72 \\
\cline { 2 - 5 } & Left & $11.0-21.3$ & 16.0 & 2.34 \\
\hline \multirow{2}{*}{ MN - MF } & Right & $16.5-28.2$ & 20.81 & 3.42 \\
\cline { 2 - 5 } & Left & $16.1-30.0$ & 21.3 & 3.61 \\
\hline \multirow{2}{*}{ MA - MF } & Right & $16.1-28.1$ & 21.31 & 2.71 \\
\cline { 2 - 5 } & Left & $15.0-29.1$ & 20.34 & 3.32 \\
\hline
\end{tabular}

Table-Ii: Study reports on mandibular foramen distance published by various authors

\begin{tabular}{|c|c|c|c|c|c|}
\hline AUTHOR & SIDE & AB-MF & PB-MF & MN-MF & MA-MF \\
\hline \multirow[t]{2}{*}{ Prado et al (2010) ${ }^{10}$} & Right & $19.2 \pm 3.6$ & $14.2 \pm 8.4$ & $23.6 \pm 3.1$ & - \\
\hline & Left & $18.8 \pm 3.8$ & $13.0 \pm 2.6$ & $23.1 \pm 3.0$ & - \\
\hline \multirow{2}{*}{$\begin{array}{l}\text { Pranjananaparamitasamanta } \\
\qquad(2013)^{11}\end{array}$} & Right & $\begin{array}{l}15.72 \pm \\
2.92\end{array}$ & $13.29 \pm 1.74$ & $22.70 \pm 30$ & $21.54 \pm 2.92$ \\
\hline & Left & $16.23 \pm 2.88$ & $12.73 \pm 2.04$ & $\begin{array}{c}22.27 \pm \\
2.92\end{array}$ & $21.13 \pm 3.43$ \\
\hline \multirow{2}{*}{$\begin{array}{l}\text { Qudusio Sultana et. al } \\
\qquad(2016)^{12}\end{array}$} & Right & $17.69 \pm 2.7$ & $11.39 \pm 1.9$ & $\begin{array}{c}23.87 \pm \\
4.5\end{array}$ & $17.9 \pm 3.5$ \\
\hline & Left & $17.94 \pm 2.7$ & $22.39 \pm 3.1$ & $\begin{array}{r}23.66 \pm \\
4.3\end{array}$ & $17.6 \pm 3.7$ \\
\hline \multirow{2}{*}{ Anil Sastya et. Al (2016) ${ }^{13}$} & Right & $\begin{array}{l}16.31 \\
\pm 2.51\end{array}$ & $\begin{array}{l}14.74 \\
\pm 2.47\end{array}$ & $\begin{array}{c}22.98 \pm \\
3.09\end{array}$ & $\begin{array}{l}26.45 \\
\pm 3.51\end{array}$ \\
\hline & Left & $\begin{array}{l}16.33 \\
\pm 2.54 \\
\end{array}$ & $\begin{array}{l}16.64 \\
\pm 2.41 \\
\end{array}$ & $\begin{array}{l}23.06 \pm \\
3.15\end{array}$ & $\begin{array}{l}26.03 \\
\pm 3.62 \\
\end{array}$ \\
\hline \multirow{2}{*}{ Present study } & Right & $\begin{array}{l}17.21 \\
\pm 1.81 \\
\end{array}$ & $16.1 \pm 1.72$ & $\begin{array}{l}20.81 \pm \\
3.42\end{array}$ & $\begin{array}{l}21.31 \\
\pm 2.71 \\
\end{array}$ \\
\hline & Left & $17.0 \pm 2.61$ & $16.0 \pm 2.34$ & $\begin{array}{c}21.3 \pm \\
3.61\end{array}$ & $\begin{array}{l}20.34 \\
\pm 3.32\end{array}$ \\
\hline
\end{tabular}

A total 65 dentulous adult dry human mandible were studied for the position of the mandibular foramen with respect to different bony landmarks. The minimum, maximum, mean and the standard deviation for each were calculated separately by the statistical formulas on the either side of the mandible. The mean distance of mandibular foramen ( MF) from

1) Anterior border of ramus of the mandible $(\mathrm{AB})$ is $17.2 \mathrm{~mm}$ on right side and $17.0 \mathrm{on}$ left side.

2) Posterior border of ramus of the mandible $(\mathrm{PB})$ is $16.1 \mathrm{~mm}$ on right side and $16.0 \mathrm{on}$ left side.

3) Mandibular notch (MN) is $20.81 \mathrm{~mm}$ on right side and $21.3 \mathrm{on}$ left side.

4) Angle of mandible (MA) is 20.3 on right side and 20.3 on the left side.

\section{Discussion}

The inferior alveolar nerve block is most often used for local anaesthetic technique for any operative procedure on mandible. The commonest reason for failure of the technique is the inappropriate location of the tip of the anaesthetic needle due to inappropriate localisation of the mandibular foramen (MF). [14-16] The anaesthesiologist have to select an appropriate needle to block inferior alveolar nerve. Averages the long needles are $23 \mathrm{~mm}$ long and short needle are $21.5 \mathrm{~mm}$ long to an appropriate mandible. Otherwise it may damage the parotid gland and its associated structures or the needle may break. So localisation of the mandibular foramen is very important to select the size of the anaesthetic needle.

According to many studies the posterior and the superior third of the ramus of the mandible constitute a "safety zone" where mandibular foramen (MF) is unlikely to be found. This area can be used on vertical ramus osteotomy (VRO) with a low incidence of inferior alveolar damage to correct the mandibular prognathism. [17] The correct localisation of mandibular foramen is of very much essential for performing a proper and safe sagittal split osteotomy (SSO) procedure on the mandible.

In our study it is seen that the mean distance of

$\mathrm{MF}$ to $\mathrm{AB}$ is $17.2 \pm 1.81 \mathrm{~mm}$ in right and $17.0 \pm 2.61 \mathrm{~mm}$ in the left,

MF to $P B$ is $16.1 \pm 1.72 \mathrm{~mm}$ in right and $16.0 \pm 2.34 \mathrm{~mm}$ in the left,

MF to MN is $20.81 \pm 3.42 \mathrm{~mm}$ in right and $20.3 \pm 3.61 \mathrm{~mm}$ in the left and

MF to MA is $21.31 \pm 2.71 \mathrm{~mm}$ in right and $20.34 \pm 3.32 \mathrm{~mm}$ in the left 
All our observations are in conformity with that of other authors (Table-II) except that MA - MF distance exceeds.

\section{Conclusion}

Though the position of the mandibular foramen is variable, it is important to keep in mind that mandibullar foramen is closer to the posterior border than the anterior border of the mandibles, also it is nearly equidistance from the gonium and the mandibular notch. The concept of exact location will help to decide the length of the needle to be preferred for the Inferior Alveolar nerve block.

\section{References}

[1]. T. Jayachandra Pillai, T Sobha Devi, C K Laxmi Devi. Studies on Human mandibles. IOSR-JDMS. 2014; 13(1-verII): 8-15.

[2]. Dr. Kanan Shah, Pratik Shah, Ajay Parmar. Study of the location of Mandibular Foramina in Indian Dry mandibles. GRA- Global Research Analysis. 2013; 21 (7): 128-130

[3]. Varsha ShenoyS vijaya laxmi, P Saraswathi. Osteometric Analysis of the Mandibular Foramen in dry mandibules. JCDR. 2012 May (Supp-2); 6(4): 557-560

[4]. Afsar. A., D. A. Hass, P. E. Rossovw and R.Wood., Radiographic localization of mandibular anaesthetic land marks. oral surgery, oral med, oral pathol, oral radiol. Endod.1998; 66: 234-241

[5]. Potocnik I. and Bajrovic F. Failure of inferior alveolar nerve block in endodontics. Endod. Dent. Traumatol. 1999; 15: 247-225.

[6]. Vinckier I. What is the cause of failures of local anaesthesia? Rev. Belge Med. Dent. 2000; 55: 41-50.

[7]. Madan G.A., Madan S.G., Madan A.D.Failure of inferior alveolar nerve block: exploring the alternatives. J. Am. Dent. Assoc. 2002; 133: 843-846

[8]. Komar,D., Lathrop.S. Frequencies of morphological characteristics in two contemporary forensic collections: implications for identification. J Forensic Sci. 2006; 51(5): 974-978.

[9]. Neiva, R.F., Gapski,R., Wang H.L. Morphometric analysis of implant-related anatomy in Caucasian skulls. J Periodontol. 2004; 75(8): 1061-1067

[10]. Pranjanasamanta. Morphometric analysis of mandibular foraman and incidence of accessory mandibular foraman in adult human mandibles in Indian population.RevArg de Anat Clin. 2013; 5 (2): 60-66.

[11]. Prado, F.B., Groppo, F.C., Volpato, M.C. and Caria, P.H.F. Morphological changes in the position of the mandibular foramen in dentate and edentate Brazilian subjects. Clin. Anat.2010; 23: 394-399

[12]. Qudusia Sultana et al. Study of surgical landmarks of mandibular foramen for inferior alveolar nerve block: An Osteological study. Indian Journal of Clinical Anatomy and Physiology 2016; 3(1): 37-40

[13]. Anil Sastya Preeti. Study of Mandibular Foramen From Different Bony Land Marks In Dry Human Mandibles. IJSR. 2016; 5(1): 62-64

[14]. Palti DG, Almeida CM, Rodrigues AC, Andreo JC, Lima Jeo. An anesthetic technique for the inferior alveolar nerve block: a new approach. J Appl Oral Sci. 2011; 19(1): 11-5.

[15]. Ennes JP, Medeiros RM. Localization of the mandibular foramen and its clinical implications. Int. J. Morphol., 2009; 27(4): 130511.

[16]. Patrical LB, Arthur HJ. The key to profound local anaesthesia. JADA 2003; 134: 753-60.

[17]. Olivier T, Vivien S, Nicolas C, Gabriel M, Pierre T. A simple method to locate the mandibular foramen: a preliminary radiological study. Surgical and Radiologic Anatomy 2010; 32 (10): 927-31. 